\title{
Utilization trends of genetic clinics excluding prenatal services in Washington State, 1995-2004
}

Grace Wang, $M P H^{1}$, and Carolyn Watts, $P h D^{2}$

\begin{abstract}
Purpose: To analyze genetic clinic utilization in Washington State and to explore factors associated with utilization. Methods: Our analysis included data from the 9 of 15 genetic clinics that consistently reported to the Washington State Minimum Data Set between 1995 and 2004. Prenatal genetics services were excluded. We described utilization with yearly counts of patients and analyze patient volume according to age, sex, and residence. Results: The total number of patients at nine genetic clinics in Washington increased from 1804 patients in 1995 to 3536 patients in 2004 with growth increasing at an average 8\% each year. Although adults aged 35 years and over comprised $14 \%$ of all patients in 1995, they comprised almost $28 \%$ in 2004. The number of females aged 35 years and older increased markedly during this time frame. Conclusion: Nine genetic clinics in Washington experienced growth in utilization and changes in the mix of patients served between 1995 and 2004. We suggest further study of how test availability, public awareness of genetics, supply of genetics providers, and changing regulations and insurance policies influence utilization of genetics clinics. Genet Med 2007:9(10):713-718.
\end{abstract}

Key Words: genetic clinics, genetic services, health policy, trends, utilization

Genetic clinics provide consultations for individuals at high risk for inherited disease as well as diagnoses and care of individuals with genetic conditions. Examples of specific services include genetic testing, risk estimation and interpretation, genetic counseling, information provision, patient and family support, and care coordination. ${ }^{1}$ Common reasons for seeking pediatric or adult genetic services at genetic clinics are presence of a known or suspected genetic disorder, chromosomal abnormality, congenital disability, mental retardation, developmental delay, or a family history of an inherited condition. ${ }^{2}$

The specialized focus of genetic clinics may make utilization particularly sensitive to research advancements related to gene discovery and to projects like the Human Genome Project. For example, the number of genes discovered between 1993 and 2003 increased from approximately 400 genes to 1600 genes. ${ }^{3}$ In turn, approximately 500 new genetic tests have become available for clinical use in the last 5 years in the United States. ${ }^{4,5}$ The increasing supply and availability of clinical genetic tests may have been associated with the 3 -fold increase in DNA-based test utilization seen in both Germany and Italy approximately between 1997 and 2002.6,7

\footnotetext{
From the ${ }^{1}$ Institute for Public Health Genetic; and ${ }^{2}$ Department of Health Services, University of Washington, Seattle, Washington.

Carolyn Watts, PhD, Department of Health Services, University of Washington, Box 357660, Seattle,WA98195(206)616-2986.E-mail:watts@u.washington.edu.

The contents of this work are solely the responsibility of the authors and do not necessarily represent the official view of NCRR, NIH, or HRSA.

Disclosure: The authors declare no conflict of interest.

Submitted for publication March 9, 2007.

Accepted for publication July 19, 2007.

DOI: 10.1097/GIM.0b013e318156abec
}

Data describing genetic clinics or utilization of genetic services in the United States are generally limited. Further, data have not been reported in recent years despite developments in genetics. For example, Mitchell and Petroski provided utilization rates of genetic clinics from 1985 to 1995 for four genetic centers comprising the Missouri Genetic Disease Program. ${ }^{8}$ In the period after this state genetic program evaluation, many developments in genetics became available in the health care market. Genetic testing for mutations in the breast cancer gene is now available for individuals at risk for breast and ovarian cancer, and direct-to-consumer marketing for genetic testing has been introduced. ${ }^{9}$

Examining and understanding utilization trends in health care contribute to improvements in patient care. Predicting changes allows providers and planners to ensure adequate supplies of services, to address barriers to care, and to use data for strategic planning. Delineating patterns also encourages study of factors, such as technological innovation and provider supply, which have an impact on growth and decline in service use. Although understanding health care trends is important for care and planning, trends in genetic clinics utilization are largely unexplored.

This study addresses two questions: How has utilization of genetic clinics in Washington State changed over the last 10 years? What factors may be associated with utilization of genetic clinics?

\section{MATERIALS AND METHODS}

This study uses the Washington State Minimum Data Set, a set of core data items and definitions developed for Regional Genetic Clinics to use in reporting genetic data to the Genetic 
Services Section of the Washington State Department of Health. It is based on a dataset originally developed in 1987 by the now disbanded Council of Regional Networks for Genetic Services. Washington State Department of Health has collected information for this dataset since 1993 from 14 of 15 genetics clinics in Washington State. Clinics provide aggregate counts of patients per year. Neither individual-level information nor patient identifiers are collected.

We limit our data to clinical patients served from 1995 to 2004 for nine genetic clinics in Washington because these nine clinics consistently provided data for each of these years. Eight of the nine clinics are located in Metropolitan Statistical Areas (MSA), as defined by the Washington State Office of Financial Management. ${ }^{10}$ Seven of the clinics are designated as state-funded regional genetic clinics. Excluded from the study were: two clinics that specialize in maternal-fetal and perinatal services, one clinic that provides services to clients in the military, and three clinics that are affiliated with regional medical centers.

Information on visits for prenatal services is collected separately from clinical genetic services. The Washington State Minimum Data Set defines prenatal patients as pregnant women who request or receive services relating to the outcome of the pregnancy with focus on the fetus. Patients receiving clinical genetic services are either nonpregnant individuals or pregnant women requesting and receiving services not focused on the fetus. Determining carrier status and prepregnancy counseling are considered clinical services. We exclude patients receiving prenatal services because these services often occur in more traditional health care settings like obstetrician offices and hospitals. Further, utilization and trends have been well described previously. ${ }^{11-15}$

Yearly counts of patients receiving clinical services provide an overview of utilization at nine genetic clinics in Washington. We also analyze utilization by patient age, gender, and residence. Residence is classified as urban or rural based on whether the Washington State Office of Financial Management defined the county of residence as an MSA. ${ }^{10}$

University of Washington Human Subjects Division approved this secondary data analysis.

\section{RESULTS}

Nine genetic clinics in Washington State experienced growth in utilization from 1995 to 2004. Excluding prenatal services, the number of patients nearly doubled from $1804 \mathrm{pa}-$ tients in 1995 to 3536 patients in 2004 with clinics experiencing an average $8 \%$ increase in patient volume each year (Fig. 1).

When examining number of patients by age, gender, and residence, we find increases by all sectors with notable increases among females, urban residents, and adults aged 35 years and over (Table 1 ).

The composition of clinic patients has changed over the course of time. The majority of patients have been females and individuals from urban counties. Clinics witnessed a small change during our study period with females accounting for $57 \%$ of patients in 2004 , up from $53 \%$ in 1995 . The data also

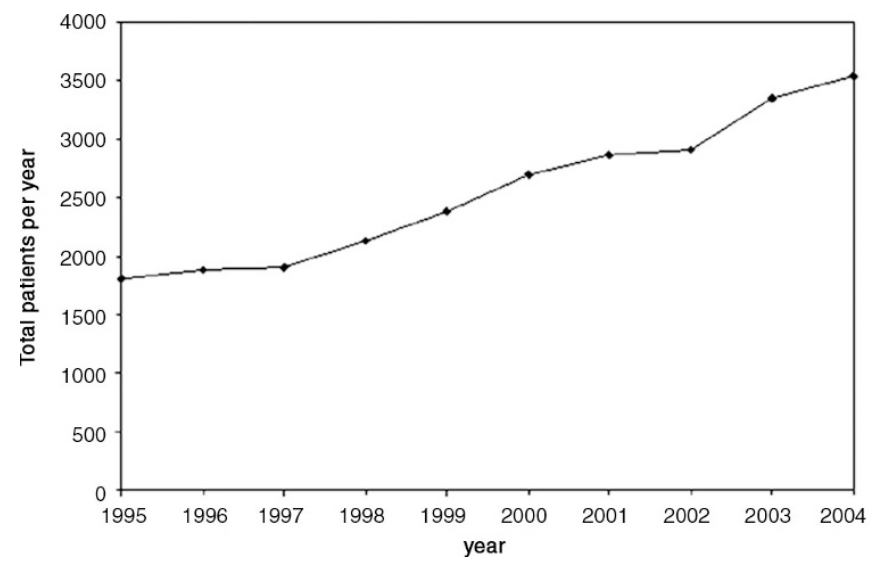

Fig. 1. Number of patients per year at nine genetics clinics in Washington State, 1995-2004.

show that individuals living in urban areas comprise approximately 70\% of patients in 1995 and $82 \%$ in 2004 .

Utilization by adults aged 35 years and over grew more than any other age category (Fig. 2). Adults aged 35 years and over comprised $14 \%$ of all patients in 1995, whereas they comprised almost $28 \%$ of patients in 2004 . Further examination showed that number of females aged 35 years and older served by clinics increased from 162 in 1995 to 743 in 2004. In contrast, the number of males aged 35 years and older increased from 92 in 1995 to 225 in 2004 (Fig. 3).

\section{DISCUSSION}

Although state population growth from 5.47 million in 1995 to 6.17 million in 2004 may have influenced clinic utilization, we identify several factors that may also explain past and future trends in genetics clinic utilization. ${ }^{16}$ We discuss how researchers can further explore each factor to increase understanding of genetics clinic utilization. Factors are organized according to Bodenheimer's framework for understanding technologic innovations and health care costs, which identifies the factors of: availability, public attitudes, acceptance by the medical profession, number of specialists in a region, regulations, and cost containment. ${ }^{17}$

\section{Availability}

The increase in number of females over the age of 35 between 1997 and 2004 may be attributable to the availability of breast cancer testing beginning in $1996 .{ }^{18}$ The likely influence of this single test on genetic clinics warrants further study of how introduction of other genetic tests into the market affects utilization. GeneTests reports that the number of diseases in the GeneTests Laboratory Directory for which genetic testing became available increased from 303 diseases in 1995 to 1071 diseases in $2004 .{ }^{5}$ However, Yoon et al. report that only a small proportion of genetic tests has the potential for public health impact. ${ }^{4}$ Further, a recent study of utilization in Italy showed that three quarters of molecular analyses conducted in 2004 referred to only 10 genes. ${ }^{7}$ If the number of tests with high 
Table 1

Annual number of patients to nine genetic clinics in Washington State, by gender, residence, and age, 1995-2004 ${ }^{a}$

\begin{tabular}{|c|c|c|c|c|c|c|c|c|c|c|}
\hline \multirow[b]{2}{*}{ Characteristic } & \multicolumn{10}{|c|}{ Year } \\
\hline & 1995 & 1996 & 1997 & 1998 & 1999 & 2000 & 2001 & 2002 & 2003 & 2004 \\
\hline Total no. patients & 1804 & 1877 & 1905 & 2134 & 2383 & 2698 & 2858 & 2903 & 3345 & 3536 \\
\hline \multicolumn{11}{|l|}{ Gender } \\
\hline Female & 951 & 984 & 952 & 1160 & 1313 & 1525 & 1583 & 1642 & 1922 & 2014 \\
\hline Male & 845 & 881 & 905 & 955 & 1067 & 1173 & 1273 & 1261 & 1422 & 1505 \\
\hline \multicolumn{11}{|l|}{ Residence $^{b}$} \\
\hline Rural & 190 & 160 & 142 & 244 & 218 & 232 & 239 & 256 & 284 & 308 \\
\hline Urban & 1250 & 1338 & 1231 & 1581 & 1528 & 1870 & 2394 & 2391 & 2650 & 2904 \\
\hline Other state & 202 & 147 & 121 & 157 & 120 & 139 & 205 & 187 & 219 & 234 \\
\hline \multicolumn{11}{|l|}{ Age } \\
\hline 0-364 days & 349 & 289 & 337 & 331 & 412 & 422 & 479 & 371 & 383 & 471 \\
\hline $1-4 \mathrm{yr}$ & 379 & 418 & 419 & 427 & 445 & 474 & 473 & 612 & 682 & 672 \\
\hline $5-9 \mathrm{yr}$ & 258 & 284 & 279 & 312 & 302 & 355 & 356 & 385 & 395 & 431 \\
\hline $10-19 \mathrm{yr}$ & 295 & 330 & 328 & 358 & 367 & 402 & 403 & 472 & 531 & 536 \\
\hline $20-34 \mathrm{yr}$ & 261 & 269 & 228 & 300 & 323 & 390 & 402 & 388 & 471 & 453 \\
\hline $35 \mathrm{yr}$ and over & 254 & 275 & 266 & 387 & 531 & 655 & 743 & 675 & 882 & 968 \\
\hline
\end{tabular}

${ }^{a}$ Number of gender, residence, age may not add to total number of patients because of missing data.

${ }^{b}$ Washington State Office of Financial Management. Metropolitan statistical areas. 2005 data book. Available at: http://www.ofm.wa.gov/databook/population/ pt05.asp. Accessed December 20, 2006.

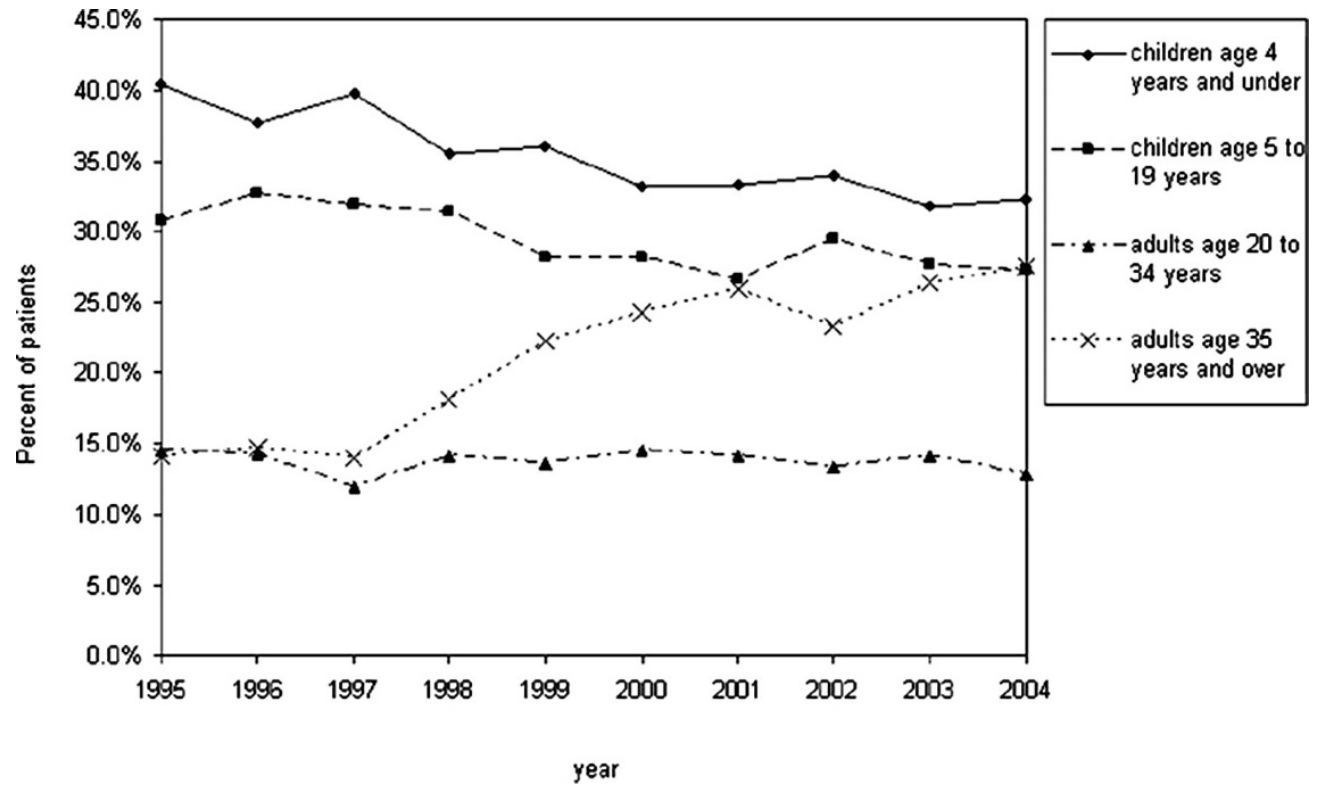

Fig. 2. Composition of clients at nine genetic clinics in Washington by age category, 1995-2004.

clinical utility shows marginal growth over time, then the increasing number of genetic tests overall may not fuel utilization of genetic clinics in the population. Future studies could determine the number of genetic tests with high clinical utility that become available each year and examine whether changes in the number of high utility products are associated with utilization growth.
Location of eight of the nine genetic clinics in MSA also helps to determine availability of services. Location combined with population growth in MSA may explain the increase in number of urban residents. ${ }^{16}$ Satellite clinics may have helped to increase availability for the residents of rural counties or other states. The emerging research on the role of telehealth in delivering genetic services will be useful to providers and plan- 


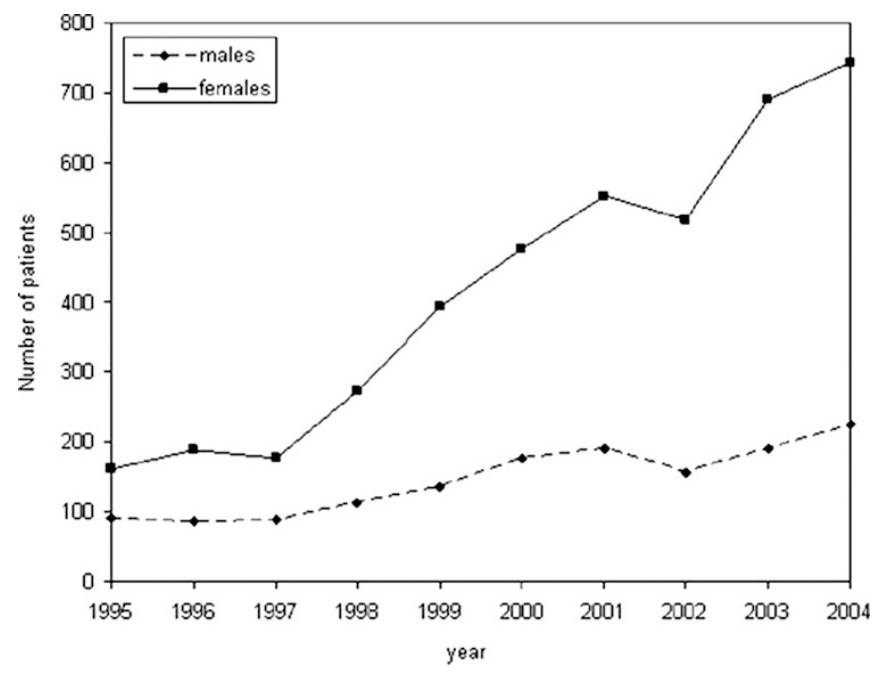

Fig. 3. Number of patients aged 35 years and older, by gender, 1995-2004.

ners when considering strategies to meet the needs of patients from geographically isolated areas. ${ }^{19-23}$

\section{Public attitudes}

We propose that increased demand for adult genetic services is another factor associated with clinics serving proportionally more adults in 2004 compared to 1995. As patients become more aware of genetics through media sources reporting on family history of diseases or through direct-to-consumer advertising, patients begin to request genetic consultations and susceptibility testing from general practitioners. ${ }^{24-27}$ Although some general practitioners will oversee genetic services themselves, many will refer to genetics clinics thereby changing the composition of genetic clinic visit patterns..$^{24,28}$

Research efforts can longitudinally monitor and assess knowledge, awareness, and attitudes toward genetics among patients to determine the impact on utilization. One possible data source is the National Health Interview Survey, which included supplemental surveys in 2000 and 2005 about cancer. Questions in the supplement related to awareness of genetic testing for cancer, family history of cancer, and recommendations to undergo genetic testing. ${ }^{29}$

\section{Acceptance by the medical profession}

Utilization by adults is a trend to which medical genetics may need to respond. Low preparation by genetic providers to meet changing demand for adult services may limit growth of clinics. As discussed at the 2004 Banbury Summit meeting on training of physicians in medical genetics, many training programs and the certification examination focus on dysmorphology, prenatal diagnosis, and biochemical genetics. ${ }^{30}$ In response, Charles Epstein urged in his American College of Medical Genetic Presidential Address, "our view of what medical genetics is and medical geneticists ought to be doing expands beyond pediatrics to encompass all of medicine and the full range of genetic disease ... We need to be as comfortable with all of the genetic issues of adults as we are with those of fetuses, infants, and children." 31

Researchers can begin to assess the effect of new training programs on utilization. For example, joint internal medicine and genetics residency programs may result in decreasing utilization of specialty genetic clinics as more general practice providers increase their skills in providing genetic services. ${ }^{32}$

\section{Number of specialists in a region}

Changing visit volume must be considered in relation to the genetic workforce. The number of genetic counselors recognized nationally by the American Board of Genetic Counseling has risen to over 2000 in the last decade. ${ }^{33}$ However, the number of new board certifications for clinical geneticists by the American Board of Medical Genetics has been declining, and current providers have reported a limited capacity to expand services. ${ }^{30,34,35}$ The American Board of Medical Genetics reports that Washington had 28 clinical geneticists, 13 biochemical or molecular geneticists, 19 cytogeneticists, and 46 genetic counselors as of 2005 for its state population of 6.26 million. ${ }^{16,34}$ Future studies could examine how number of providers and number of providers by type are associated with utilization. For example, did number of clinical geneticists act as a limiting factor to utilization growth? To what type of provider was the increasing number of clinic visits? Studies could also evaluate utilization in relation to fluctuations in the workforce supply of nongenetic specialty providers, such as obstetriciangynecologists and oncologists. Finally, future studies could examine whether and how provider capacity at genetic clinics drives patients to demand genetic services from general practitioners in the community or from alternative, Internet-based services. ${ }^{36,37}$

\section{Regulations}

A variety of state regulations may influence utilization of genetic services at clinics. First, legislation that prohibits employment discrimination (like Washington's 2004 law) and insurance discrimination, or that protects patient privacy, may increase the public's use of services. ${ }^{38}$ Second, regulations to expand newborn screening panels will have downstream consequences to utilization of genetics clinics. If Washington opts to increase its current panel from 10 disorders to the recommended 29 disorders, clinics may experience another shift in patient composition as well as an increase in visits. ${ }^{39}$ Third, changes in the state's licensure policies may also affect utilization of genetic counseling at clinics. Legislators in Washington, as well as six other states, introduced bills in 2005-2007 related to licensing of genetic counselors. ${ }^{40}$

\section{Cost containment}

Researchers may use evidence-based coverage policies or health maintenance organization (HMO) penetration in a region to evaluate cost containment. Evolving coverage of genetic services by local insurers can both hinder and facilitate access to genetic clinics, thereby affecting utilization. 


\section{Limitations}

Although this study provides information over 10 years for several genetic clinics in Washington, there are several limitations. First, this analysis does not include prenatal services. Changes in prenatal testing technology and new guidelines for prenatal services are also likely to influence utilization of genetic services and affect administration of genetic clinics. ${ }^{41}$

This analysis cannot take into consideration the patients seeking care from genetic clinics or other sources not included in our analysis. It also does not capture services provided by providers outside of the regional genetic clinic system.

By reporting number of patients per year, we do not show the extent of change in visit volume for genetic clinics. Although visit count may be inferred from number of patients, number of patients underestimates the total number of visits that the nine clinics experienced during this time frame. The trends that we show may have an even more substantial impact on clinic administration because each patient may have multiple visits to clinics.

We are unable to conduct patient-level analyses because of the nature of the data. Including patient-level information in future studies and data collection efforts would be useful for studies on access and barriers to receiving services. It would allow clinics to determine how frequently patients return to genetics clinics for ongoing care over the course of several years and use genetic clinics as medical homes. In addition, patientlevel information would provide data for examining trends on why patients were referred. For example, we are presently unable to determine whether a visit by an adult was for an adult onset condition like cancer.

Finally, the nine clinics in our analysis may not represent all genetic clinics in Washington, and genetic services utilization in Washington may not reflect service utilization in other states. Other states may have experienced different utilization trends during this period because each state has a unique demographic composition, geography, and history with genetics.

\section{CONCLUSION}

Nine genetic clinics in Washington State have experienced growth in utilization and changes in the mix of patients served between 1995 and 2004. The increasing number of females aged 35 years and over suggests that providers and planners need to strategize carefully to meet changing demand for services, particularly adult services. Multiple factors may work synergistically to influence utilization of genetics clinics. Of particular importance are: genetic test availability, increasing public awareness of genetics, supply of genetic and nongenetic providers, provider preparation to meet the genetic needs of adults, and changing regulations and insurance policies in the states. We recommend that future studies examine how these factors alone and together influence genetic clinic utilization.

\section{ACKNOWLEDGMENTS}

Supported by Grant T32 RR023256 from the National Center for Research Resources (NCRR), a component of the Na- tional Institutes of Health (NIH). This project was also supported in part by Projects U35MC02601 and U35MC02602 from the Maternal and Child Health Bureau (Title V, Social Security Act), 11223, Health Resources and Services Administration (HRSA), Department of Health and Human Services.

We gratefully acknowledge Debra Lochner Doyle and Amber Roche for their data collection efforts and for their insight into this analysis.

\section{References}

1. Department of Health, National Health Service. Specialised services national definition set: 20 medical genetic services (all ages). Specialised services definition. Last modified February 9, 2007. Available at: http://www.dh.gov.uk/en/Policyandguidance/ Healthandsocialcaretopics/Specialisedservicesdefinition/DH_4001694. Accessed September 11, 2007.

2. Washington State Department of Health. Genetic Services Section, Maternal and Child Health Programs. Last modified August 22. Available at: http://www. doh.wa.gov/CFH/mch/Genetics/ Accessed December 19, 2006.

3. National Human Genome Research Institute. Cumulative pace of gene discovery 1981-2003. Available at: http://www.genome.gov/Pages/News/PaceofDiseaseGene Discovery.pdf Accessed April 5, 2006.

4. Yoon PW, Chen B, Faucett A, Clyne M, et al. Public health impact of genetic tests at the end of the 20th century. Genet Med 2001;3:405-410.

5. University of Washington. GeneTests: medical genetics informational resource (database online). 1995-2006. http//:www.genetests.org Accessed August 21, 2006.

6. Schmidtke J, Pabst B, Nippert I. DNA-based genetic testing is rising steeply in a national health care system with open access to services: a survey of genetic test use in Germany, 1996-2002. Genet Test 2005;9:80-84.

7. Dallapiccola B, Torrente I, Morena A, Dagna-Bricarelli F, et al. Genetic testing in Italy, year 2004. Eur J Hum Genet 2006;14(8):911-916.

8. Mitchell JA, Petroski G. Evaluation of a statewide program in genetic diseases. Am J Med Genet 1998;78:217-225.

9. Genetic testing for breast and ovarian cancer susceptibility: evaluating direct-toconsumer marketing-Atlanta, Denver, Raleigh-Durham, and Seattle, 2003. MMWR Morb Mortal Wkly Rep 2004;53:603-606.

10. Washington State Office of Financial Management. Metropolitan statistical areas. 2005 data book. Last modified January 19. Available at: http://www.ofm.wa.gov/ databook/population/pt05.asp Accessed December 20, 2006.

11. Khoshnood B, Blondel B, Breart G, Lee KS, et al. Comparison of the use of amniocentesis in two countries with different policies for prenatal testing: the case of France and the United States. Prenat Diagn 2005;25:14-19.

12. Rosenberg D, Handler A, Furner S. A new method for classifying patterns of prenatal care utilization using cluster analysis. Matern Child Health J 2004;8:19-30.

13. Muggli EE, Halliday JL. Prenatal diagnostic testing and Down syndrome in Victoria 1992-2002. Aust NZ J Public Health 2004;28:465-470.

14. Wortelboer MJ, De Wolf BT, Verschuuren-Bemelmans CC, Reefhuis J, et al. Trends in live birth prevalence of down syndrome in the Northern Netherlands 1987-1996: the impact of screening and prenatal diagnosis. Prenat Diagn 2000;20:709-713.

15. National Newborn Screening and Genetics Resource Center. National Newborn Screening and Genetics Resource Center. Last modified March 24. Available at: http://genes-r-us.uthscsa.edu/ Accessed April 3, 2006.

16. State of Washington Office of Financial Management. Frequently requested population items. Available at: http://www.ofm.wa.gov/forecasting/key2pop.asp Accessed August 21, 2006.

17. Bodenheimer T. High and rising health care costs. Part 2: technologic innovation. Ann Intern Med 2005;142:932-937.

18. Kolata G. Breaking ranks, lab offers test to assess risk of breast cancer. NY Times (Print) 1996:A1, A15.

19. Stalker HJ, Wilson R, McCune H, Gonzalez J, et al. Telegenetic medicine: improved access to services in an underserved area. J Telemed Telecare 2006;12:182-185.

20. Meck JM, Munshi G, Plempel J, Amato S, et al. Cytogenetic analysis using telemedicine consultation: an improved means of providing expert cross-coverage. Genet Med 1999;1:328-331.

21. Lea DH, Johnson JL, Ellingwood S, Allan W, et al. Telegenetics in Maine: successful clinical and educational service delivery model developed from a 3-year pilot project. Genet Med 2005;7:21-27.

22. Coelho JJ, Arnold A, Nayler J, Tischkowitz M, et al. An assessment of the efficacy of cancer genetic counselling using real-time videoconferencing technology (telemedicine) compared to face-to-face consultations. Eur J Cancer 2005;41:2257-2261.

23. Abrams DJ, Geier MR. A comparison of patient satisfaction with telehealth and 
on-site consultations: a pilot study for prenatal genetic counseling. J Genet Couns 2006;15:199-205.

24. Wideroff L, Freedman AN, Olson L, Klabunde CN, et al. Physician use of genetic testing for cancer susceptibility: results of a national survey. Cancer Epidemiol Biomarkers Prev 2003;12:295-303.

25. Sifri R, Myers R, Hyslop T, Turner B, et al. Use of cancer susceptibility testing among primary care physicians. Clin Genet 2003;64:355-360.

26. Mouchawar J, Hensley-Alford S, Laurion S, Ellis J, et al. Impact of direct-to-consumer advertising for hereditary breast cancer testing on genetic services at a managed care organization: a naturally-occurring experiment. Genet Med 2005;7:191-197.

27. Armstrong K, Weiner J, Weber B, Asch DA. Early adoption of BRCA1/2 testing: who and why. Genet Med 2003;5:92-98.

28. Pichert G, Dietrich D, Moosmann P, Zwahlen M, et al. Swiss primary care physicians' knowledge, attitudes and perception towards genetic testing for hereditary breast cancer. Fam Cancer 2003;2:153-158.

29. Centers for Disease Control and Prevention. National Health Interview Survey (NHIS). Available at: http://www.cdc.gov/nchs/nhis.htm Accessed June 29, 2007.

30. Korf BR, Feldman G, Wiesner GL. Report of Banbury Summit meeting on training of physicians in medical genetics, October 20-22, 2004. Genet Med 2005;7:433-438.

31. Epstein CJ. Medical geneticists in the 21st century. Genet Med 2005;7:375-379.

32. American Board of Internal Medicine. Internal medicine/medical genetics. Available at: http://www.abim.org/cert/commgen.shtm Accessed June 28, 2007.
33. American Board of Genetic Counseling. History. Available at: http://www.abgc.net/ english/View.asp? $x=1607$ Accessed June 29, 2007.

34. American Board of Medical Genetics. About the ABMG. Available at: http://www. abmg.org/genetics/abmg/about.htm Accessed June 29, 2007.

35. Cooksey JA, Forte G, Benkendorf J, Blitzer MG. The state of the medical geneticist workforce: findings of the 2003 survey of American Board of Medical Genetics certified geneticists. Genet Med 2005;7:439-443.

36. Cooksey JA, Forte G, Flanagan PA, Benkendorf J, et al. The medical genetics workforce: an analysis of clinical geneticist subgroups. Genet Med 2006;8:603-614.

37. Alsever J. The gene screen. Diagnosis: advances in the field of genomics are creating new tests for diseases and drug reactions. Business 2.0 magazine. Last modified October 3. Available at: http://money.cnn.com/2006/09/26/magazines/business2/ 8387104.biz2/?postversion $=2006092706$ Accessed November 10, 2006.

38. RCW 49.44.180. Genetic screening. Available at: http://apps.leg.wa.gov/RCW/ default.aspx? cite=49.44.180 Accessed June 29, 2007.

39. American College of Medical Genetics. Newborn screening: toward a uniform screening panel and system. Available at: http://mchb.hrsa.gov/screening/ Accessed June 29, 2007.

40. National Conference of State Legislatures. Genetics legislation database. Available at: http:// www.ncsl.org/programs/health/genetics/geneticsdb.cfm Accessed June 29, 2007.

41. ACOG Practice Bulletin No. 77: screening for fetal chromosomal abnormalities. Obstet Gynecol 2007;109:217-227. 